\title{
Doxorubicin Impacts the Chromatin Binding of Hmgb1, Histone H1 and Retinoic Acid Receptor
}

Rosevalentine Bosire

University of Debrecen

Lina Fadel

University of Debrecen

Gábor Mocsár

University of Debrecen

Péter Nánási

University of Debrecen

Pialy Sen

University of Debrecen

Anshu Kumar Sharma

University of Debrecen

Muhammad Umair Naseem

University of Debrecen

Attila Kovács

University of Debrecen

Jennifer Kugel

University of Colorado

Guido Kroemer

Université de Paris, Institut Universitaire de France

György Vámosi

University of Debrecen

Gábor Szabó ( $\nabla$ szabog@med.unideb.hu )

University of Debrecen

\section{Research Article}

Keywords: Doxorubicin, Chromatin Binding, Retinoic Acid Receptor

Posted Date: January 5th, 2022

DOI: https://doi.org/10.21203/rs.3.rs-1203312/v1 
License: (c) (i) This work is licensed under a Creative Commons Attribution 4.0 International License. Read Full License 
DOXORUBICIN IMPACTS THE CHROMATIN BINDING OF HMGB1, HISTONE H1 AND RETINOIC ACID RECEPTOR

Rosevalentine Bosire ${ }^{1,2}$, Lina Fadel ${ }^{1,3}$, Gábor Mocsár ${ }^{1}$, Péter Nánási ${ }^{1}$, Pialy Sen ${ }^{1,3}$, Anshu Kumar Sharma $^{1}$, Muhammad Umair Naseem ${ }^{1,3}$, Attila Kovács ${ }^{4}$, Jennifer Kugel ${ }^{5}$, Guido Kroemer ${ }^{6,7,8}$, György Vámosi ${ }^{1 *} \&$ Gábor Szabó ${ }^{1 *}$

${ }^{1}$ Department of Biophysics and Cell Biology, Faculty of Medicine, University of Debrecen, Debrecen, Hungary

${ }^{2}$ Doctoral School of Molecular Cell and Immune Biology, University of Debrecen, Debrecen, ${ }^{3}$ Doctoral School of Molecular Medicine, University of Debrecen, Debrecen, Hungary Hungary

${ }^{4}$ Department of Radiation Therapy, Faculty of Medicine, University of Debrecen, Debrecen, Hungary

${ }^{5}$ Department of Biochemistry, University of Colorado, Boulder, U.S.A.

${ }^{6}$ Centre de Recherche des Cordeliers, Equipe labellisée par la Ligue contre le cancer, Université de Paris, Sorbonne Université, Inserm U1138, Institut Universitaire de France, Paris, France

${ }^{7}$ Metabolomics and Cell Biology Platforms, Institut Gustave Roussy, Villejuif, France

${ }^{8}$ Pôle de Biologie, Hôpital Européen Georges Pompidou, Paris, AP-HP, France

*Equal senior, corresponding authors: szabog@med.unideb.hu, vamosig@med.unideb.hu

\begin{abstract}
Doxorubicin (Dox), a widely used anticancer DNA-binding drug, affects chromatin in multiple ways, and these effects contribute to both its efficacy and dose-limiting side-effects, especially cardiotoxicity. Here we studied the Dox effects on the chromatin binding of the architectural proteins high mobility group B1 (HMGB1) and the linker histone H1, and the transcription factor retinoic acid receptor (RAR $\alpha$ ) by fluorescence recovery after photobleaching (FRAP) and fluorescence correlation spectroscopy (FCS), in live cells. At lower drug concentrations, Dox increased the binding of HMGB1 to DNA while decreasing the binding of the linker histone H1. At higher doses that correspond to the peak plasma concentrations reached in chemotherapy, Dox reduced the binding of HMGB1 as well. This biphasic effect is interpreted in terms of a hierarchy of competition between the ligands involved and Dox-induced local conformational changes of nucleosome-free DNA. When combined, FRAP and FCS mobility data suggest that Dox
\end{abstract}


decreases the overall binding of RAR $\alpha$ to DNA, an effect that was only partially overcome by agonist binding. The intertwined interactions described likely contribute to the effects as well as side-effects of Dox.

\section{INTRODUCTION}

We have previously noted that the toroid nucleosomal superhelicity of genomic DNA is a powerful impediment to the intercalative binding of small molecules to native chromatin and concluded that the structural constraint imposed by the nucleosome on the DNA wrapped around it, rather than limitations to diffusional access, are likely to control ligand binding ${ }^{1}$. In contrast, the nucleosomefree regions including the internucleosomal linker DNA were readily bound by the same dyes meaning that the plectonemic superhelicity of these regions easily adapts to accommodate such ligands ${ }^{1}$. These findings spurred us to investigate how small molecule intercalators influence the binding of proteins known to target these regions, including structural constituents of chromatin, high-mobility group protein B1 (HMGB1) and the linker histone H1, as well as a sequence-specific transcription factor, retinoic acid receptor (RAR).

DNA binding proteins recognize the DNA base sequence (base readout) and the structural features of DNA (shape readout) as determinants of their target sites $^{2}$. The structural features include parameters describing intra-base pair and inter-base pair ${ }^{3,4}$ spatial relationships as well as minor groove dimensions (width and depth). Although they are sequence-dependent, they can also be altered by factors such as DNA supercoiling and binding of drugs. For example, the binding of intercalating drugs such as doxorubicin (Dox), increases the inter-base pair distance and untwists the DNA, which in a closed DNA molecule results also in changes in writhe. Importantly, the structural features are interdependent, e.g. changes in DNA twist affect the groove widths ${ }^{5}$. This implies that topological changes, while partitioning into twist and writhe, would affect the shape read-out of a particular protein.

Histone H1 and HMGB1 both bind to the linker DNA where it enters/exits the nucleosomal core particle but exert opposing effects on chromatin structure ${ }^{6}$. Whereas histone H1 stabilizes nucleosome structure and facilitates higher order chromatin folding ${ }^{7}$, binding of HMGB1 enhances nucleosome sliding and decompacts chromatin ${ }^{8}$. Consequently, histone $\mathrm{H} 1$ represses transcription, 
contrasting with HMGB1 which promotes the interaction of transcription factors (TFs) with DNA. Although both proteins bind to DNA without sequence specificity, their binding is influenced by DNA structure. Histone $\mathrm{H} 1$ preferentially binds to superhelical plasmid DNA in vitro, a fact that may be explained by its increased potential to form multiple H1-DNA contacts on plectonemically wound DNA 9 . HMGB1 preferentially binds to pre-bent DNA, supercoiled DNA, damaged DNA, hemicantenanes \& cantenanes, four-way junctions and other non-B DNA structures in vitro ${ }^{10}$. Upon binding, HMGB1 further bends the DNA towards the major groove by an angle of about $77^{\circ}$. This bending results from the intercalation of three hydrophobic amino acids through the minor groove $\mathrm{e}^{11,12}$.

In sharp contrast to the aforementioned structural proteins, TFs recognize and bind specific sequences positioned immediately upstream of the transcription start site or far away from the promoter, to modulate gene transcription ${ }^{13}$. With the exception of pioneer factors, TFs are able to engage with their binding sites only within nucleosome-free regions. Upon TF-DNA interaction the DNA undergoes deformations such as bending and/or kinking to accommodate the $\mathrm{TF}^{14}$. Since bending demands energy, TFs preferentially bind to pre-bent DNA structures or DNA that is easily deformable ${ }^{15}$.

Retinoic acid receptor (RAR) is a member of the nuclear receptor (NR) family of TFs the activation of which is ligand-dependent. RAR requires heterodimerization with retinoid X receptor (RXR) for proper transactivation of its target genes. In chromatin, RAR-RXR heterodimeric complexes recognize a specific sequence called retinoic acid response element (RARE) composed of a direct repeat (DR) of AGGTCA sequences separated by a spacer of either 1, 2 or 5 bases, termed DR1, DR2 and DR5, respectively. Binding occurs through the major DNA groove ${ }^{16}$.

The mechanism of action of RAR and other nuclear receptors can be explained by the molecular switch model. In the presence of its agonist (all-trans RA, ATRA, or 9-cis RA), RAR recruits coactivator complexes and activates transcription, whereas in the absence of an agonist it binds corepressors with histone deacetylase activity ${ }^{17}$. Previously, we have shown by fluorescence correlation spectroscopy (FCS) measurements that in contrast with the original static model, RAR (as well as RXR) is dynamic. Its diffusion in the nucleus can be described by a model assuming a fast, freely diffusing component corresponding to monomers or small complexes, and a slow, chromatin-bound component. Agonist treatment increased the slow fraction in a coactivator- 
dependent manner and enhanced dimerization with $\mathrm{RXR}^{18-21}$. In view of our ChIP-seq data, ligand treatment can enhance the binding of NRs to their response elements on DNA ${ }^{18,21}$. The genes controlled by the RAR-RXR heterodimer include topoisomerase II $\beta$ (TopII $\beta$ ), which is suppressed by the binding of the heterodimer to a RARE positioned $907 \mathrm{bp}$ downstream of the TopII $\beta$ transcription start site $^{22}$ linking RAR signalling and Dox-induced TopII $\beta$ cleavage complexes to cardiotoxicity, a major hazard when applying the drug for the treatment of human malignances ${ }^{23}$. Whether and how Dox may also influence the DNA-binding properties of RAR has not been determined before.

DNA binding of these proteins was studied in live cells, using FRAP that gives information about the average diffusion properties within a larger area, over distances of a few $\mu \mathrm{m}-\mathrm{s}$, and FCS, which reflects local diffusion behavior and binding within a diffraction-limited sensitive volume smaller than $1 \mu \mathrm{m}^{3}$ within a lateral radius of $\sim 200 \mathrm{~nm}$. Binding of all of these proteins was insensitive to topological relaxation itself. On the other hand, intercalators, including Dox, an anthracyclin widely used in cancer chemotherapy, had a robust and biphasic effect by interfering with $\mathrm{H} 1$ binding and thereby facilitating the association of HMGB1 with DNA at low-to-moderate Dox concentrations, and by directly competing with all the proteins investigated at higher drug concentrations. Our findings provide insights into the interplay of ligand binding to native chromatin and add further items to the long list of the cellular effects of anthracyclins. Particularly intriguing among these is the overall reduction of RAR binding since the retinoic acid signaling pathway has emerged recently as a major player in doxorubicin-induced cardiotoxicity (DIC) ${ }^{24,25}$.

\section{RESULTS}

\section{The anticancer drug Doxorubicin impacts HMGB1 distribution and mobility in the nuclei of live cells}

Treatment of $\mathrm{U}^{2 \mathrm{OS}^{2 \mathrm{FP}}}$ cells with Dox caused a loss of GFP-HMGB1 from nucleoli while its distribution at the chromatin became more structured (Fig. 1a). However, at a Dox concentration of $>9 \mu \mathrm{M}$, the structured distribution in the chromatin was lost and the localization of GFPHMGB1 became more diffuse. This biphasic effect on chromatin distribution was also reflected by the mobility of GFP-HMGB1 measured by point FRAP.The recovery time increased with 
increasing Dox concentration peaking at about $50 \mathrm{~ms}$ for samples treated with $4.5 \mu \mathrm{M}$ and then declined at higher Dox concentrations (Fig. 1b). Similar observations were made following treatment with another intercalating drug ethidium bromide (EBr) (Fig. S1).

a

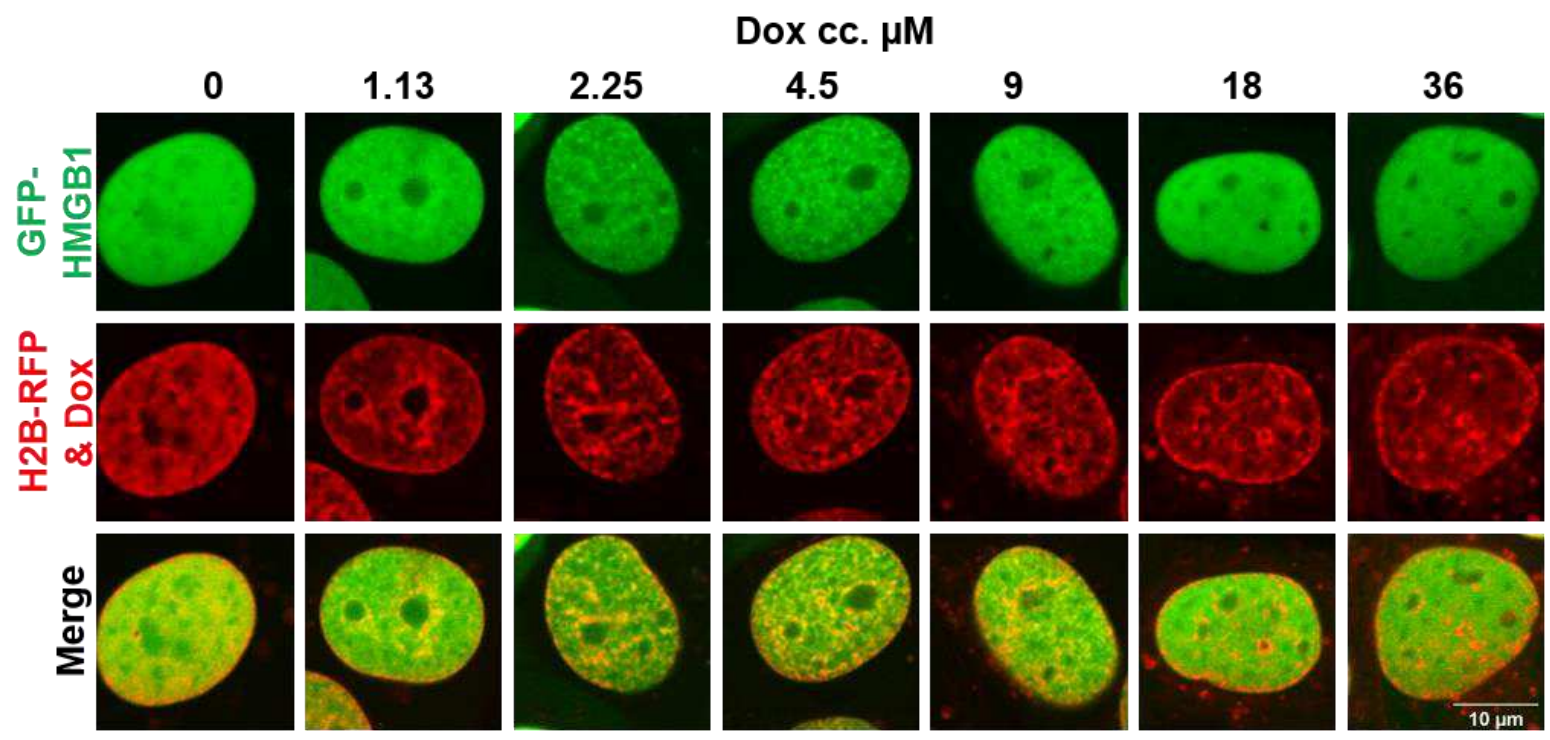

b

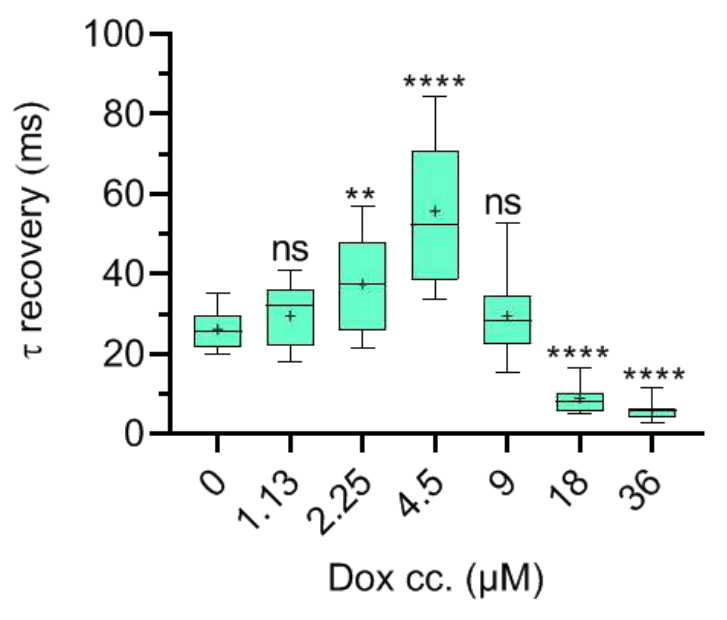

Figure 1: Doxorubicin affects HMGB1 dynamics in a concentration dependent manner. a) Representative nuclei of $\mathrm{U}_{2} \mathrm{OS}^{2 \mathrm{FP}}$ cells treated with the indicated concentrations of Dox for $2 \mathrm{hrs}$. b) GFP-HMGB1 recovery times of Dox-treated cells as measured by point FRAP. The graph shows one representative experiment of three repeats. In this as well as in the other figures, boxand-whiskers plots represent $10^{\text {th }}, 25^{\text {th }}, 50^{\text {th }}, 75^{\text {th }}$, and $90^{\text {th }}$ percentiles; + , mean value. One-way 
ANOVA with post hoc Dunnett's test was used to calculate significance compared to 0 Dox $(* * \mathrm{p}<0.01, * * * * \mathrm{p}<0.0001)$. Data were analyzed using GraphPad Prism 8.01.

Drug intercalation to DNA increases the base pair rise while reducing the helix twist by an angle dependent on the intercalator molecule. This decrease in helix twist translates into an overall reduction in DNA twist, which is compensated by an increase in writhe within the chromatin loops ${ }^{1}$. To elucidate the possible contribution of superhelicity to the recovery profiles generated above (Fig. 1b \& Fig. S1), we induced topological relaxation by nicking agents.

\section{DNA nicking had no effect on HMGB1 binding in live cells}

In view of the well-known winding effect of intercalators ${ }^{26,27}$ (and refs therein), we tested the possible role of internucleosomal superhelicity in determining HMGB1 binding in vivo. DNA supercoiling was relaxed by treating live U2OS ${ }^{2 \mathrm{FP}}$ cells with hydrogen peroxide $\left(\mathrm{H}_{2} \mathrm{O}_{2}\right)$, bleomycin or X-ray irradiation, and GFP-HMGB1 binding to DNA was evaluated by point FRAP. Given the short time interval between nicking and measurement, we expected that the breaks would still be unrepaired, or even if they were, the original levels of internucleosomal superhelicity would not have been reestablished. Thus, if HMGB1 binding were sensitive to supercoiling, relaxation would affect its binding. Strikingly, none of these agents caused a change in FRAP recovery rate (Fig. 2), suggesting that intercalators influence HMGB1 binding directly rather than indirectly by changing twist-writhe partitioning. 
a

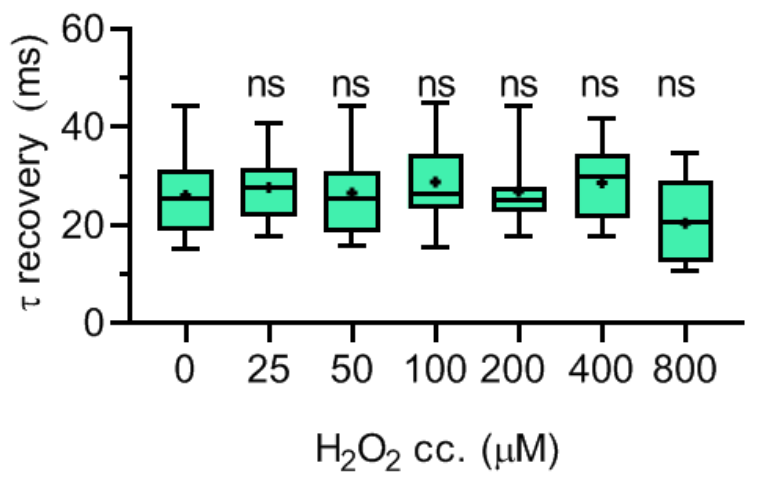

b
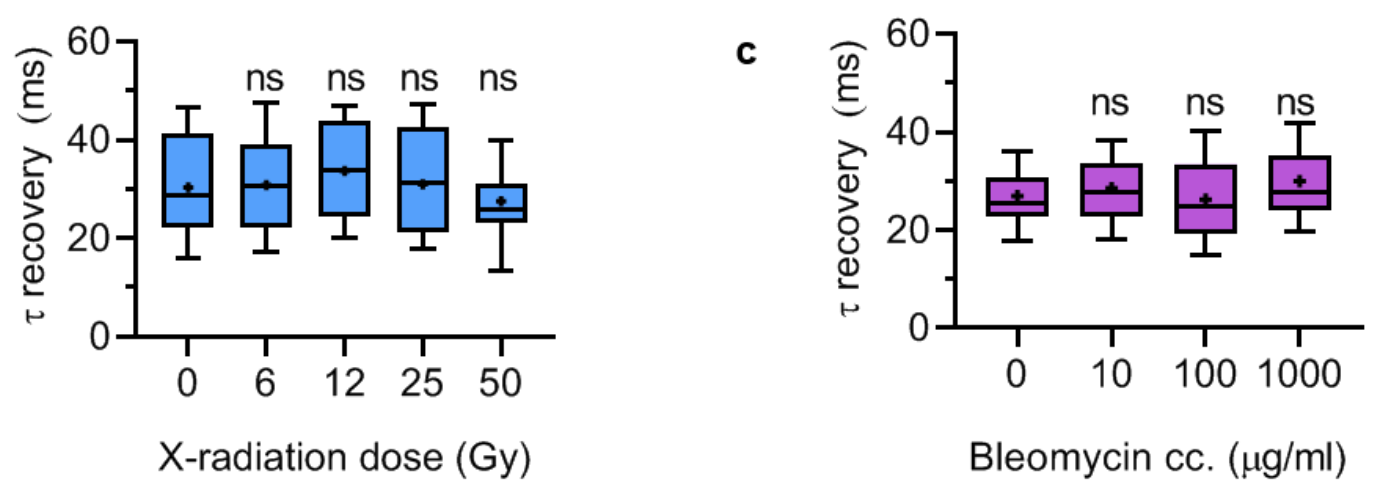

Figure 2: Relaxation of supercoiling by nicking does not affect chromatin binding of HMGB1. $\mathrm{U}_{2} \mathrm{OS}^{2 \mathrm{FP}}$ cells were treated with a) 25, 50, 100, 200, 400 and $800 \mu \mathrm{M} \mathrm{H}_{2} \mathrm{O}_{2}$ for 20 minutes, or b) with 10,100 and $1,000 \mu \mathrm{g} / \mathrm{ml}$ bleomycin for $2 \mathrm{hrs}$, or c) irradiated with 6, 12, 25 and 50 Gy X-ray, then the mobility of GFP-HMGB1 was measured by point FRAP. Graphs show one representative experiment of three repeats. The statistical test used is one-way ANOVA $(\alpha<$ $0.05)$.

The lack of effect of DNA supercoiling on HMGB1 binding in live cells was surprising since there was a slight but clear difference between the topological forms of plasmid DNA in their ability to bind rHMGB1, when all the forms were simultaneously present (Fig. S2). As seen on the gel image, the migration of supercoiled plasmid DNA was retarded by as low as 60:1 rHMGB1-toplasmid molar ratio and this retardation became more pronounced with increasing amounts of rHMGB1. Migration of linear DNA was not affected by up to a somewhat higher (100:1) proteinto-plasmid ratio, indicating a slightly lower rHMGB1-binding affinity for linear as compared to supercoiled DNA. 


\section{Dox decreases the binding of HMGB1 to supercoiled plasmid DNA}

The diffusion constant (D) of rHMGB1 in solution was $73 \mu \mathrm{m}^{2} / \mathrm{s}$ as determined by FCS. In the presence of native plasmid DNA, two diffusing components were observed: a fast component corresponding to freely diffusing rHMGB1 D $76 \mu \mathrm{m}^{2} / \mathrm{s}$ and a slow component D $4 \mu \mathrm{m}^{2} / \mathrm{s}$, which was interpreted to be DNA-bound HMGB1 based on the fact that the diffusion constant of Sybr Gold stained native plasmid DNA was $3 \mu \mathrm{m}^{2} / \mathrm{s}$ (Fig. 3a). Addition of increasing concentration of Dox led to a monotonous decrease in the fraction of HMGB1 bound to plasmid DNA (Fig 3b). This finding suggests that Dox may directly compete with HMGB1 binding.
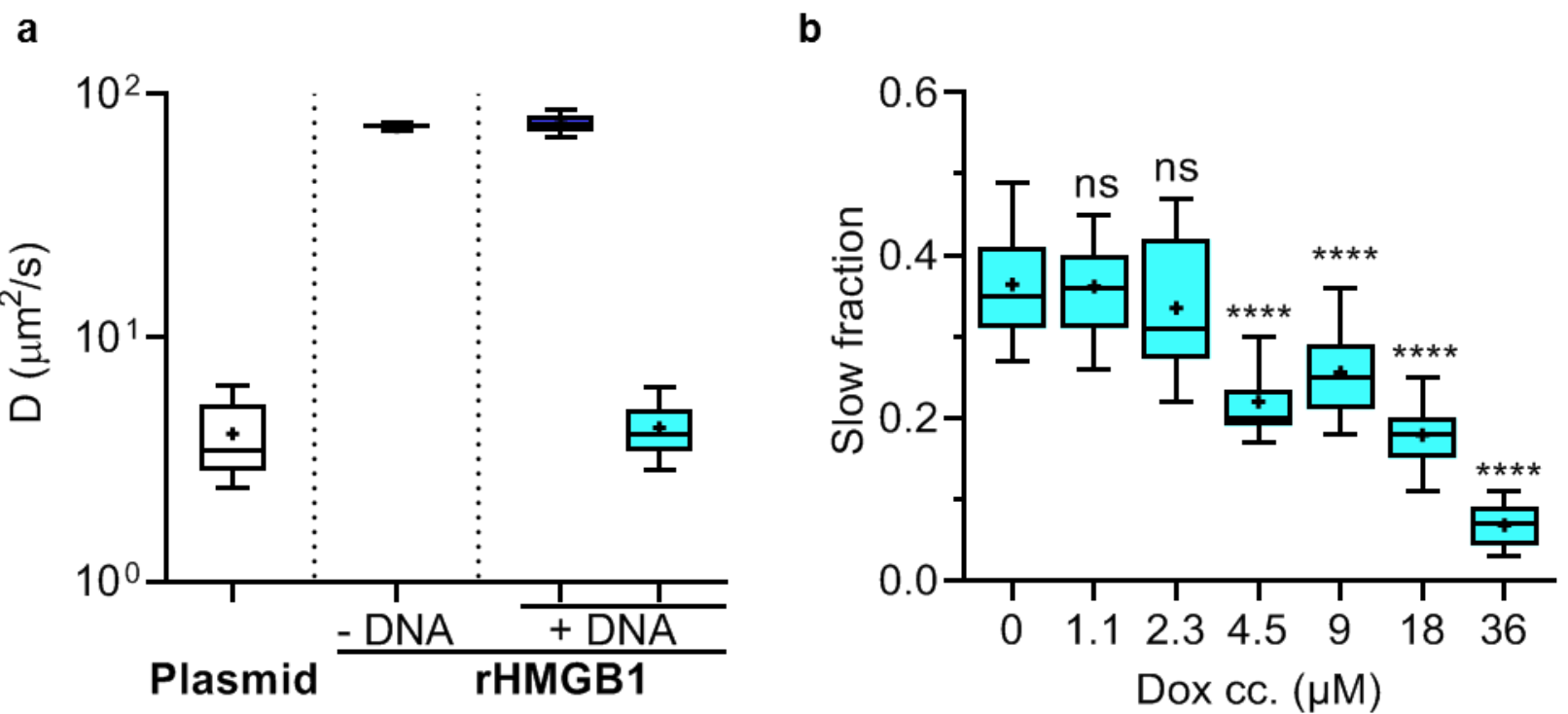

Figure 3: Dox decreases the binding of rHMGB1 to plasmid DNA in solution. a) Diffusion coefficient of SYBR Gold stained native plamid DNA and of Alexa-647 labelled rHMGB1 in solution and in the presence of supercoiled plasmid DNA as measured by FCS. b) Fraction of rHMGB1 bound to supercoiled plasmid DNA in the presence of varying concentrations of Dox. One-way ANOVA with post hoc Dunnett's test was used to calculate significance $* * * * p<0.0001$.

\section{Dox displaces histone $\mathrm{H1}$ from chromatin in live cells}

Previous studies have shown that HMGB1 competes with histone $\mathrm{H} 1$ for binding to the linker DNA near the nucleosome dyad ${ }^{6}$. Furthermore, Daunomycin, a drug structurally similar to Dox can evict the linker histone variant H1.1 from chromatin ${ }^{28}$. H1.1 is one of the human somatic histone $\mathrm{H} 1$ variants the expression of which is replication-dependent. However, unlike H1.2, H1.3, 
H1.4 and H1.5 that are ubiquitously expressed, expression of H1.1 is limited to certain tissues ${ }^{29}$. To determine if Dox had a similar effect, HeLa cells expressing GFP tagged H1c, a mouse ortholog of human H1.2, were treated with increasing concentration of Dox and the distribution and mobility of the histone were assessed. The effect of Dox on H1c binding in vivo was both time and concentration dependent. Within $30 \mathrm{~min}$, large-scale Dox-induced eviction of H1c-GFP from chromatin and its redistribution towards nucleoli was observed (Fig. 4a). This effect was accompanied by an increased mobility as measured by strip FRAP (Fig. 4b). After 2 hrs of Dox treatment, the nucleolar component disappeared and there was a generalized loss of H1c-GFP from the cell (Fig. 4a). Similarly, EBr caused displacement of H1c-GFP from chromatin (Fig. S3). The displacement of histone H1 from DNA likely increases the number of available HMGB1 binding sites in the genomic DNA, thus explaining its recruitment to chromatin and the slower recovery rates in the first phase of the bimodal response (Fig. 1b and Fig. S1).

a

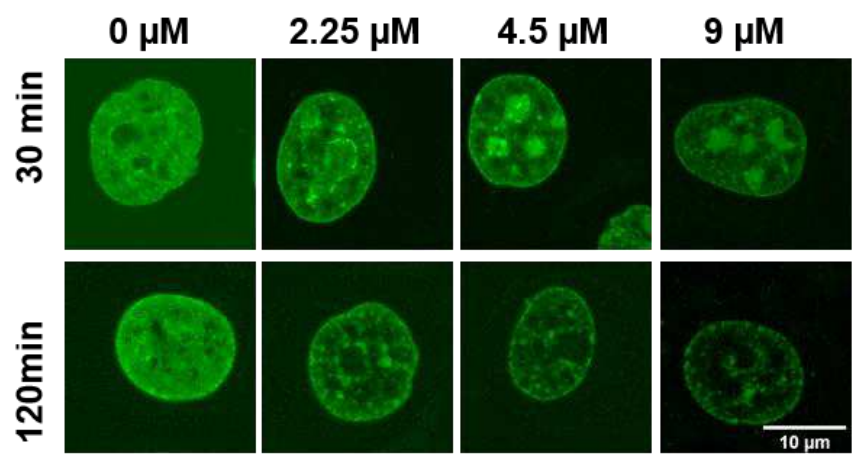

b

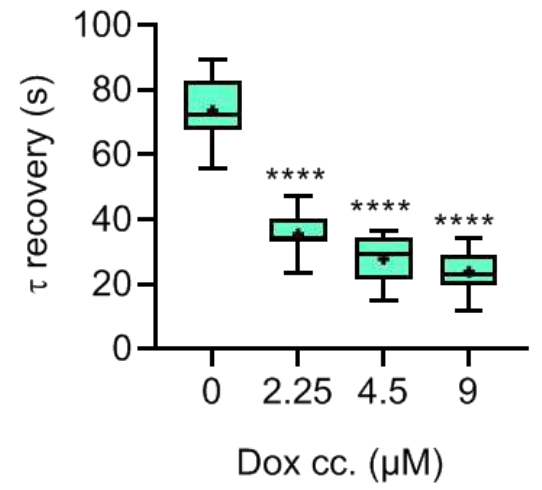

Figure 4: Doxorubicin affects histone H1c binding to genomic DNA in a dose- and timedependent manner.a) Representative images of H1c-GFP expressor HeLa cells treated with Dox for 30 (top row) or 120 minutes (bottom row). b) FRAP analysis of H1c-GFP intranuclear mobility without Dox treatment and after 30 minutes treatment with different concentrations of the drug. One-way ANOVA with post hoc Dunnett's test was used to calculate significance $(* * * * \mathrm{p}<0.0001)$

\section{Dox affects the binding of RAR $\alpha$ to DNA}


To assess if intercalators affect the DNA binding of TFs, we extended our studies to the nuclear receptor RAR $\alpha$. RAR $\alpha$ binds to DNA in a sequence-specific manner via its zinc-finger motif not involving intercalating amino acids. Strip-FRAP was used to analyse the average mobility of RAR $\alpha$ over distances of several micrometers. Our FRAP data could be fitted to a biexponential model function (see equations 2-5, for FRAP curves see Fig. S4). Fig. 5 shows the diffusion behaviour in terms of the weighted average of the recovery times, $\tau_{\text {average }}$; the detailed behaviour of the individual components is shown in Fig. S5. With increasing doses of Dox, the overall mobility of RAR $\alpha$ increased, i.e., its DNA-binding decreased as suggested by the reduced $\tau_{\text {average }}$. At $1.125 \mu \mathrm{M}$ Dox concentration it was only slightly reduced, whereas at $4.5 \mu \mathrm{M}$ it decreased from $1.43 \mathrm{~s}$ to $0.94 \mathrm{~s}$. A further reduction in RAR $\alpha$ binding was observed at $18 \mu \mathrm{M}$ concentration to 0.67 s. The mobile pool (Fig. S5d) decreased slightly, from $98 \%$ for the control to $~ 93 \%$ for 18 $\mu \mathrm{M}$ of Dox. Treatment with the specific RAR $\alpha$ agonist AM580 (used at $0.1 \mu \mathrm{M}$ concentration) ameliorated the reduction in RAR binding up to $4.5 \mu \mathrm{M}$ Dox concentration, while $\tau_{\text {average }}$ was reduced to $0.69 \mathrm{~s}$ upon treatment with $18 \mu \mathrm{M}$ (Fig. 5, right). For further details see Fig. S5.

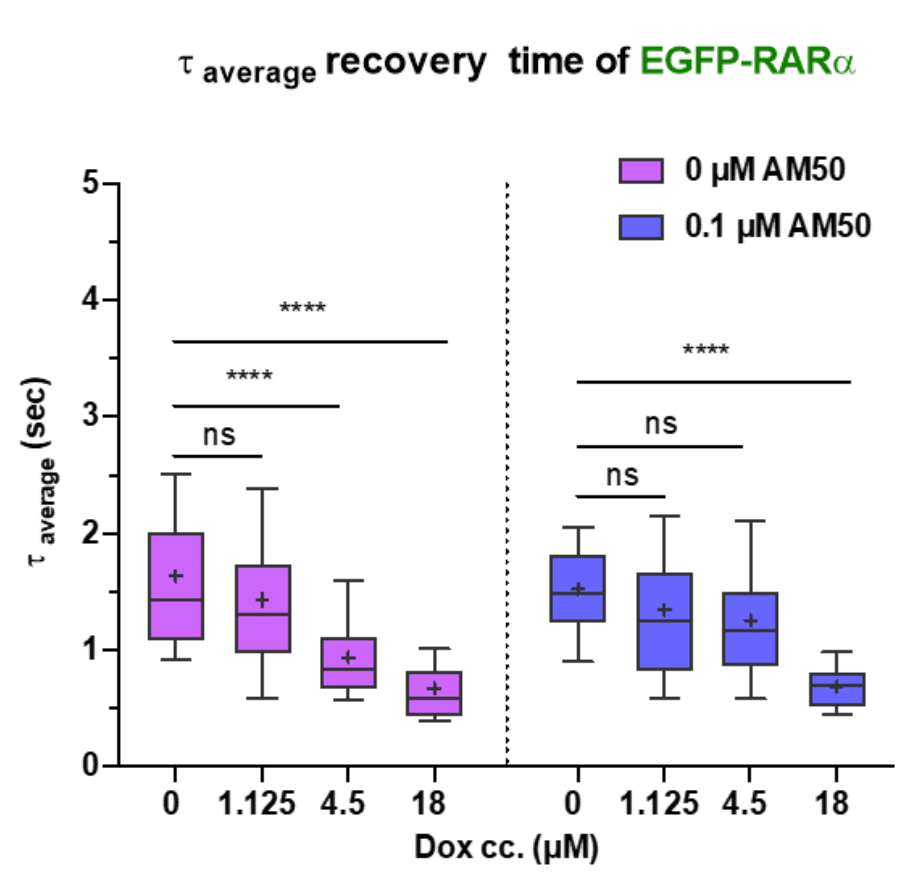

Figure 5: Dox reduces RAR $\alpha$ binding to DNA in vivo. Average recovery times of EGFP-RAR $\alpha$ derived from strip FRAP experiments in cells treated with different concentrations of doxorubicin $(0,1.125,4.5,18 \mu \mathrm{M})$ in the presence or absence of the RAR-specific agonist AM580 used at 0.1 
$\mu \mathrm{M}$. Two-way ANOVA with Tukey's multiple comparison test was used to calculate significance; $* \mathrm{p}<0.05, * * \mathrm{p}<0.01, * * * \mathrm{p}<0.001, * * * * \mathrm{p}<0.0001$.

To assess if the observed increase in RAR mobility was due to a change of microviscosity in the nucleus, we applied FRAP to the EGFP dimer, an inert molecule not binding to DNA. Its recovery time was not affected by Dox treatment (see Fig. S6) indicating that microviscosity was not significantly altered.

To reveal the subcellular distribution of the chromatin and EGFP-RAR $\alpha$, confocal images were taken. The distribution of EGFP-RAR $\alpha$ exhibited only mild spatial variations, whereas that of Dox was more heterogeneous displaying very bright and dark areas (Fig. 6a).

The uneven distribution of Dox prompted us to probe the local mobility of EGFP-RAR $\alpha$ with FCS, an approach capable of distinguishing ligand-specific RAR binding through the fraction of the slow component of the autocorrelation curves ${ }^{19}$. The slow, DNA-bound fraction of RAR $\alpha$ in control and ligand and/or Dox-treated cells is shown in Fig. 6b. Treatment with $4.5 \mu \mathrm{M}$ of Dox alone had no effect on the proportion of the slow fraction, whereas the RAR-specific agonist AM580 (used at $0.1 \mu \mathrm{M}$ ) enhanced it from $30 \%$ to $44 \%$, similar to our earlier observations ${ }^{19}$. The ligand induced increase in the slow fraction was reduced if the cells were also treated with Dox. (For further details see Fig. S7). We also measured the local mobility of the EGFP dimer by FCS. The FCS-derived diffusion coefficient displayed no significant change upon 4.5 $\mu \mathrm{M}$ Dox treatment either (Fig. S7c). 
a
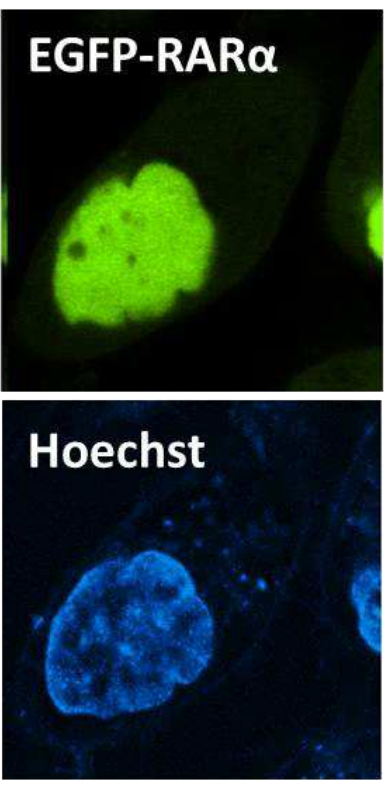
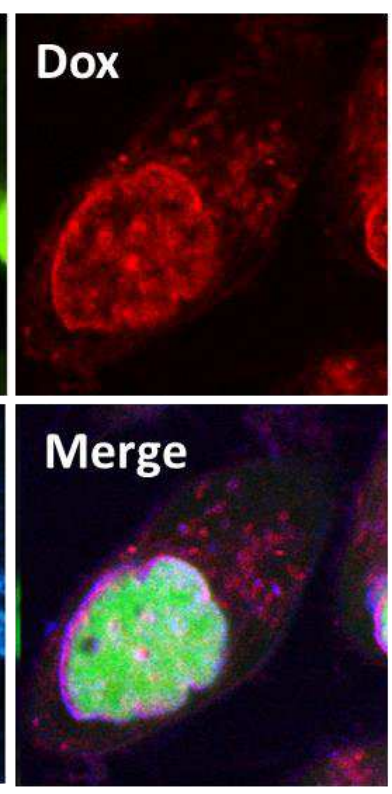

b

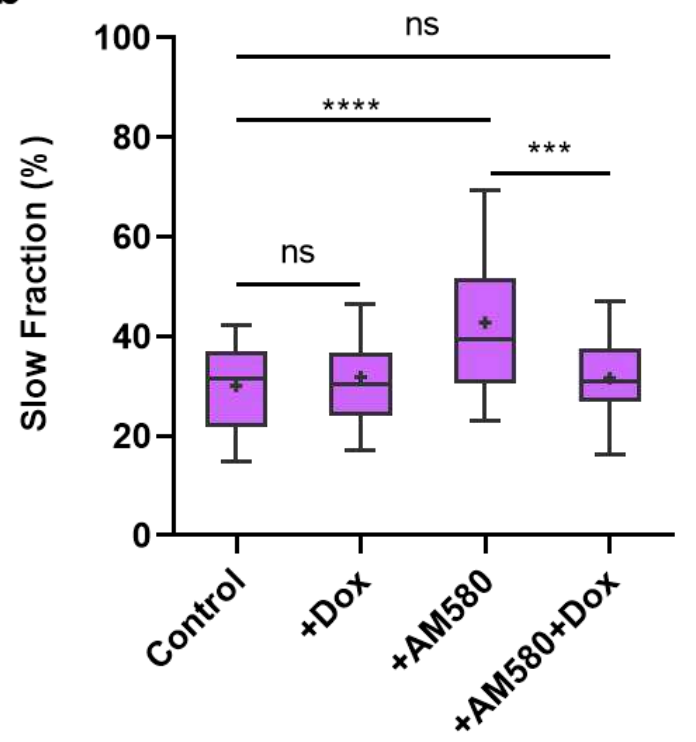

Figure 6: Doxorubicin reduces agonist-induced DNA-binding of RAR $\alpha$. a) Representative confocal images of the distribution of stably expressed EGFP-RAR in Dox-treated (4.5 $\mu \mathrm{M}) \mathrm{HeLa}$ cells, along with the distribution of Dox staining and Hoechst counterstaining. b) Fraction of the slow component of EGFP-RAR determined from FCS measurements on HeLa cells; control, treated with $4.5 \mu \mathrm{M}$ doxorubicin, with $0.1 \mu \mathrm{M}$ RAR-specific agonist AM580, or both, as indicated on the figure. Two-way ANOVA with Tukey's multiple comparison test was used to calculate significance; $* * * \mathrm{p}<0.001, * * * * \mathrm{p}<0.0001, \mathrm{~ns}$, not significant.

\section{DNA nicking has no effect on RAR $\alpha$ diffusion}

We have also evaluated if DNA superhelicity has an effect on the binding of RAR $\alpha$ in vivo, using $200 \mu \mathrm{M} \mathrm{H}_{2} \mathrm{O}_{2}$ as a nicking agent to relax the supercoiled genomic DNA. As a negative control, the diffusion of the EGFP dimer, transiently expressed in HeLa cells, was evaluated. The diffusion coefficient of the EGFP dimer (D 20 $\mu \mathrm{m}^{2} / \mathrm{s}$, see Supplementary Figs. S8a and S9) was unaffected by $\mathrm{H}_{2} \mathrm{O}_{2}$ treatment. This implies that $\mathrm{H}_{2} \mathrm{O}_{2}$ did not alter the structure of the chromatin in a manner that would influence the diffusion rate of a nuclear protein having no binding site in chromatin. Next, we analysed the effect of $\mathrm{H}_{2} \mathrm{O}_{2}$ on RAR $\alpha$ binding. Treatment with $\mathrm{H}_{2} \mathrm{O}_{2}$ did not change either the diffusion coefficient (Fig. S8b, c) or the proportions of the fast and slow fractions of RAR $\alpha$ (Fig. S8d). $\mathrm{H}_{2} \mathrm{O}_{2}$ had no significant effect on these parameters in AM580 treated cells either. Thus, 
we conclude that DNA relaxation by nicking does not affect the RAR-binding capacity of the chromatin $^{30}$.

\section{DISCUSSION}

Here we report that Dox intercalation into DNA in vivo affects HMGB1 binding to DNA in a bimodal fashion, i.e. increasing binding of the protein at lower concentrations, and causing a drastic reduction at concentrations higher than $9 \mu \mathrm{M}$ (Fig. 1). The phase of increased HMGB1 binding is well explained by histone $\mathrm{H} 1$ displacement from DNA in view of the facts that $\mathrm{H} 1$ and HMGB1 compete for the linker DNA near the nucleosome dyad ${ }^{6}$. In line with this notion, histone H1 exhibits higher sensitivity to intercalator binding than HMGB1, i.e. H1 is readily displaced from chromatin by both $\mathrm{EBr}$ and Dox at drug concentrations where HMGB1 is still bound to DNA (compare Fig. 4 with Figs. 1 and Fig. S1).

The reduction in HMGB1 binding to DNA at high Dox concentrations (Fig. 1b) could be due to intercalator induced DNA distortion, or alternatively, to competition between Dox and HMGB1 for binding sites on DNA. Dox carries two DNA binding moieties, the anthraquinone moiety which intercalates between adjacent G-C base pair steps, and the amino sugar which is positioned in the DNA minor groove ${ }^{31}$. Intercalation of the anthraquinone moiety increases the base pair rise to 5.2 $\AA$ and reduces the helical twist at the site of intercalation. In vivo, unwinding of the DNA due to intercalation would be compensated for by positive writhing within the closed chromatin loops without change in the linking number, in line with the equation $\Delta L k=\Delta T w+\Delta W r$. The level of the compensatory positive torsion would increase with the number of intercalated molecules. This intercalator-induced change in torsion together with that induced by ongoing replication and transcription would trigger topoisomerase activity to resolve it, as reviewed $\mathrm{in}^{32,33}$. However, at high concentrations $(>9 \mu \mathrm{M}$ ), Dox would inhibit the binding of the topoisomerase to DNA (as reviewed $\mathrm{in}^{34}$ ), thus leading to accumulation of positive writhe. Although some of the positive torsion may be annihilated by the negative torsion stored in nucleosome-bound DNA following destabilization of nucleosomes ${ }^{35,36}$, this may reduce but not completely abrogate positive torsion. The positive writhe would thus hinder the binding of HMGB1, which involves intercalation ${ }^{37}$. This argument would be in line with the monotonous reduction in HMGB1 binding to covalently closed plasmid DNA in the presence of Dox (Fig. 3b). However, the lack of any detectable change in 
HMGB1 binding upon nicking treatments suggests that the contribution of the above mechanism to the decreased binding may not be significant. Thus, local distortion of DNA conformation or competition of the two ligands for DNA are suggested to account for the results of Figure $3 \mathrm{~b}$.

Regarding the latter type of interaction, the binding of Dox and HMGB1 to DNA overlap in two aspects: both involve intercalation into DNA as well as minor groove binding. HMGB1 possesses two DNA binding domains, box A and B, which are connected by a short linker to an intrinsically disordered, acidic C-terminal tail ${ }^{38}$. The A and B domains form an "L"-shape with a concave DNA binding surface. The binding of HMGB1 to DNA occurs through the DNA minor groove and induces a bend towards the major groove. Additionally, hydrophobic amino acids phenylalanine (Phe38) on box A, phenylalanine (Phe1103) and isoleucine (Ile122) on box B partially intercalate between base pairs following DNA binding, and unwind the $\mathrm{DNA}^{37}$. This overlap in the Dox and HMGB1 binding to DNA is bound to create grounds for competition.

Even at the highest concentration of EBr used $(100 \mu \mathrm{M})$, HMGB1 binding to DNA exceeded that of the control, as seen in the microscopy images and also through the point FRAP profiles (Fig. S1). This is in sharp contrast to Dox, which at drug concentrations $>9 \mu \mathrm{M}$ reduces HMGB1 binding to DNA.This effect may be attributed to the lower uptake of EBr by live cells due to its positive charge, which means that the amount of dye intercalated in DNA is much lower than in the case of Dox. Doxorubicin is known to accumulate in cells attaining a higher intracellular concentration as compared to the extracellular milieu. Another factor in the higher efficiency of Dox to suppress HMGB1 binding may be the presence of the amino sugar positioned in the DNA minor groove.

Relaxing DNA writhe in chromatin loops by nicking via X-ray irradiation, treatment with $\mathrm{H}_{2} \mathrm{O}_{2}$ or bleomycin did not yield any observable effect on the binding of HMGB1 in vivo (Fig. 3). This is in contrast with the well documented preference of HMGB1 binding to supercoiled over relaxed DNA in vitro (Fig. S2; see also ${ }^{37}$ ). At the dosage used in these experiments, X-ray irradiation is estimated to cause $6,000-50,000$, while $\mathrm{H}_{2} \mathrm{O}_{2}$ provokes $15,000-36,000$ single strand breaks per nucleus ${ }^{39,40}$. E303030ven if a fraction of single strand breaks may be repaired within minutes ${ }^{41}$, many of the breaks would remain unrepaired given the short time interval between nicking and measurement. Moreover, it appears unlikely that the initial level of supercoiling could be restored by RNA and DNA polymerization according to the twin supercoil model ${ }^{42}$ in these circumstances. 
The fact that HMGB1 binding in vivo was not affected by DNA nicking implies that the protein binds similarly to relaxed and supercoiled DNA when it is the only conformation available. Furthermore, the overall negative supercoiling of internucleosomal DNA may be much smaller than that of the supercoiled plasmid. Therefore, the topological preference of the protein emphasized earlier based on in vitro data ${ }^{37}$ is probably irrelevant in the cellular context.

Other groups have observed nuclear to cytoplasmic translocation or extracellular secretion of HMGB1 from immune cells following ionizing radiation or $\mathrm{H}_{2} \mathrm{O}_{2}$ treatment, at doses lower than those used here ${ }^{43,44}$. This, however, occurred 3-24 hours after exposure, i.e. after most of the single strand breaks would have been repaired and thus cannot be directly related to changes in superhelicity or H1 binding.

The evidence presented here suggests that supercoiling may not affect HMGB1 binding in vivo, or any effect of supercoiling may be overshadowed by interactions involving the chromatin environment, as follows. In the context of the general rules governing ligand binding to chromatin, although the nucleosome-constrained topology and the interrelated structural features of the DNA pose a powerful obstacle of ligand access to $\mathrm{DNA}^{1}$, binding to the flexible internucleosomal DNA regions is, in general, not determined by DNA topology; here competition among the ligands or distortion of the DNA structure around the bound anthracyclin seem the dominant controlling factors. The concentration dependent influence of Dox on HMGB1 binding has not been recognized before and may contribute to the effects and side-effects of this medically relevant anthracycline.

We also analyzed how Dox treatment affects the DNA binding of a sequence-specific TF, RAR $\alpha$. This TF is unlikely to have an effect on the balance of H1 and HMGB1 genome-wide, i.e. its effects must be restricted to the regulatory regions of RAR responsive genes. On the other hand, upon ligand dependent RAR binding, HMGB1 may be recruited at these sites while H1 is displaced $^{45}$ This exchange would be facilitated by Dox at low drug concentrations where it evicts H1 without affecting HMGB1 binding, leading perhaps to augmented RAR binding. However, such an effect, if it occurred, was apparently overcome by the decrease in DNA binding, seen also in the absence of the ligand (Fig. 5).

We measured the mobility of EGFP-RAR $\alpha$ on a distance scale of a few micrometers, averaged for larger areas, with FRAP (Fig. 5, Fig. S5), and on a shorter distance scale of a few hundred 
nanometers, locally, with FCS (Fig. 6b, Fig. S7). The FRAP recovery curves likely reflect the extent of overall DNA binding, while being also influenced by the diffusional constraints. The latter may be altered upon Dox treatment that is known to elicit gross morphological changes in the nucleus due to histone eviction and consequential aggregation ${ }^{35}$. With both methods we could detect a fast and a slow component, and with FRAP an additional fraction appearing as "immobile" over the distance scale of FRAP. The FRAP-detected fast and slow components refer to molecules that leave the few-micrometer wide ROI during the time course of the measurement, thus, both are diffusible and even the slow component may only be transiently DNA-bound. In view of our earlier FCS studies in this system ${ }^{18-21,46}$, the fast FCS component may likely be identified with the fast component of FRAP, which probably represents the freely diffusing RAR species or what is bound to DNA for very short dwell times, $\sim 1 \mathrm{~ms}$ according to our FCS fits (Fig. S9). The slow FCS component likely corresponds to transiently DNA-bound RAR (dwell time on the order of several hundreds of milliseconds) as well as stably bound RAR moving slowly together with the chromatin. The slow FCS component is likely a mixture of the slow and "immobile" populations detected by FRAP. Similar slow diffusion coefficients were detected by FCS for other DNAbinding proteins as well ${ }^{46-48}$.

Our most noteworthy observation via FRAP was that Dox increased the average mobility of RAR $\alpha$ (Fig. 5). This increase was confirmed to be due to shorter dwell times spent DNA-bound rather than to a change of microviscosity, since the diffusion coefficient of the EGFP dimer was not affected (Fig. S6). On the other hand, Dox slightly enhanced the immobile fraction (decreased the mobile fraction) in a dose-dependent manner (Fig. S5d). This is in line with the decrease of the FCS-determined slow diffusion coefficient attributed to DNA-bound receptors (Fig. S7b). Thus, Dox seems to have a dual effect on the DNA-binding of RAR $\alpha$. First, there is a prominent Doxinduced decrease of overall RAR binding to the DNA, and second, a much smaller fraction of RAR displays decreased mobility. This latter minor component may be due to a stronger DNAbinding of the TF to the dehistonized DNA visible in the Dox-reorganized nuclei ${ }^{35}$.

Previously, we have shown by FCS, FCCS and FRET that the RAR agonist AM580 augmented heterodimerization of $\mathrm{RAR} \alpha$ with $\mathrm{RXR} \alpha$, increased the proportion of the slow fraction and enhanced its DNA-binding ${ }^{19-21}$. Here, treatment with saturating concentrations $(0.1 \mu \mathrm{M})$ of AM580 partly counteracted the effect of Dox on the average mobility of RAR $\alpha$, i.e. the reduction of the 
average FRAP recovery time was mitigated in the presence of the ligand at a Dox concentration of up to $4.5 \mu \mathrm{M}$, which is within the range of the therapeutic doses ${ }^{49}$. Our FCS measurements reveal that Dox, used at a concentration easily reached in the tissues during chemotherapy ${ }^{36}$, overcomes the ligand-induced increment of the slow fraction, while not affecting it in the absence of the ligand (Fig. 6b). Thus, Dox decreases ligand-independent as well as ligand-dependent RAR binding, based on FRAP and FCS data, respectively.

The reduction in binding of RAR $\alpha$ following Dox treatment may suggest yet another mechanism by which Dox may exert its cytotoxicity. As the binding of RAR $\alpha$ to DNA does not involve intercalation, and there was no effect of nicking on RAR binding (Fig. S8), the reduction may be explained by either direct competition between Dox and RAR for the binding sites on the DNA or the drug's effect on its structural features. For example, Dox intercalation increases the stiffness of the $\mathrm{DNA}^{50}$ and hence may decrease DNA deformability that is required for optimal TF binding ${ }^{16}$.

Despite the high efficacy of Dox in treating malignancies, its therapeutical use is limited by cardiotoxicity ${ }^{51}$. Several studies have linked Dox induced cardiotoxicity (DIC) to topoisomerase poisoning, while others emphasize the role of ROS production ${ }^{24}$. RAR $\gamma$ was recently shown to bind to the Top2 $\beta$ gene at a retinoic acid response element (RARE) positioned downstream of the transcription start site, thereby repressing gene transcription in the presence of ATRA. However, in cells expressing the nonsynonymous SNP variant RAR $\gamma$-S427L, this transrepression is compromised, thus aggravating DIC ${ }^{22,25}$. Indeed, correction of this RAR $\gamma$-S427L SNP by genetic engineering reduced the cytotoxicity of Dox ${ }^{52}$. Based on these findings, we propose that Doxinhibited RAR binding to chromatin may contribute to cardiotoxicity. We speculate that a separate, rather than combined, administration of ATRA and Dox could mitigate DIC, while not affecting Dox cytotoxicity in cancer cells where the role of RAR signalling in Top2 $\beta$ control may not be relevant or tight.

In summary, Dox, at $\leq 4.5 \mu \mathrm{M}$ concentration, augments HMGB1 binding by causing $\mathrm{H} 1$ eviction, while strongly inhibiting HMGB1 binding at higher doses also reached in blood plasma levels during chemotherapy. In addition, Dox reduces RAR $\alpha$ binding, thus affecting a TF that contributes to the pathogenesis of DIC. 


\section{MATERIALS AND METHODS}

Cell culture: HeLa cells stably expressing GFP-tagged histone $\mathrm{H} 1$ (HeLa $\left.^{\mathrm{H} 1 \mathrm{c}-\mathrm{GFP}}\right)$ and $\mathrm{U} 2 \mathrm{OS}$ cells stably expressing GFP-tagged HMGB1 and RFP-tagged H2B (U2OS ${ }^{2 F P}$ ), (kindly provided by Profs. Hiroshi Kimura, Tokyo and Guido Kroemer, Paris, respectively) were maintained in DMEM medium (Gibco) supplemented with 10\% FBS 1x GlutaMAX, $100 \mathrm{U} / \mathrm{ml}$ penicillin, $100 \mu 1 / \mathrm{ml}$ streptomycin and phenol red. In addition, media for $\mathrm{U}_{20 \mathrm{O}^{2 \mathrm{FP}}}$ cells was supplemented with G418 $0.5 \mathrm{mg} / \mathrm{mL}$ for continuous selection of transformed cells. HeLa cells and HeLa cells stably expressing EGFP-RAR $\alpha$, (HeLa ${ }^{\text {EGFP-RAR } \alpha}$ ) were maintained in RPMI supplemented with phenol red, $10 \%$ fetal calf serum (Sigma-Aldrich, Saint Louis, MO), 1× GlutaMAX (Fisher Scientific, Tokyo, Japan), and $50 \mathrm{mg} / \mathrm{l}$ gentamycin (KARA, Novo Mesto, Slovenia). All cells were cultured at $37^{\circ} \mathrm{C}$ in a humidified, $5 \% \mathrm{CO} 2$ incubator and passaged every two days.

For microscopy experiments, HeLa or HeLa ${ }^{\text {EGFP-RAR } a}$ cells were seeded in 8-well chambered cover slips (ibidi GmbH, Gräfelfing, Germany) $48 \mathrm{~h}$ before the measurement and maintained in phenol red-free RPMI supplemented with 10\% charcoal-stripped fetal calf serum (PAN-Biotech, Aidenbach, Germany).

Transfection: $24 \mathrm{hrs}$ after seeding, HeLa cells reached 50-60\% confluency and were transiently transfected with $80 \mathrm{ng}$ of EGFP dimer for FRAP experiment and $40 \mathrm{ng}$ for the FCS experiments using FuGENE® HD transfection reagent (Promega, MA, USA) as suggested by the manufacturer.

Cell treatment: Cells were treated with the indicated concentrations of either Dox for $2 \mathrm{hrs}$ (Sigma Aldrich), $\mathrm{EBr}$ for $1 \mathrm{hr}$, bleomycin for $2 \mathrm{hrs}$ or $\mathrm{H}_{2} \mathrm{O}_{2}$ for $20 \mathrm{~min}$ at $37^{\circ} \mathrm{C}$ in phenol red-free medium. Irradiation with X-rays was done at room temperature at a distance of $57.6 \mathrm{~cm}$ from the window of a $6 \mathrm{MeV}$ linear accelerator (Radiotherapy Department, University of Debrecen). AM580 was applied to the cells at $100 \mathrm{nM}$ final concentration for $30 \mathrm{~min}$ at $37^{\circ} \mathrm{C}$ before imaging.

Point FRAP: When it was made possible by the kinetics of recovery, point FRAP was used to better detect possible spatial heterogeneities. For measurement of GFP-HMGB1 mobility, point FRAP measurements were performed on an Olympus FluoView 1000 confocal microscope based on an inverted IX-81 stand with an UPlanAPo 60× NA 1.2 oil immersion objective. EGFP was excited by the $488 \mathrm{~nm}$ line of an Ar-ion laser, and emission was detected through a 500-520 nm band-pass filter by a PMT. The measurement for point FRAP data acquisition started with a 
confocal image of a cell (512×512-pixel, pixel size: $0.103 \mu \mathrm{m})$, followed by the selection of a laser spot at which the laser beam was focused. Before bleaching, 5120 pre-bleach pixels were collected with a pixel dwell time of $10 \mu \mathrm{s}(51.2 \mathrm{~ms})$ followed by bleach period for $51.2 \mathrm{~ms}$ with $100 \%$ laser power $55.6 \mu \mathrm{W}$ and then collecting 40,000 post-bleach pixels from the same spot for a total time of $297.59 \mathrm{~ms}$.

In order to change the laser power of the Ar-ion laser shorter than the pixel dwell time, a dedicated LabVIEW program was developed. The analogue output of a NI 7833 field programmable gate array (FPGA) card (National Instruments, Austin, TX) was fed into the laser power controller input pin of the acousto-optic tunable filter (AOTF, AA Opto electronic MOD.NC) of the laser combiner unit, allowing fast $(\sim 1 \mu \mathrm{s})$ voltage driven laser power switching by an FPGA card. The operating of the FPGA card was initiated by a TTL output of the trigger port of the FV1000 system, thus controlling the laser power and collecting the fluorescence data were synchronized.

The model function fitting of the recovery post-bleach data was performed by a custom-written Matlab (The Math Works, Natick, MA) program. Data were fitted assuming a one-component exponential recovery with the following equation:

$$
I(t)=I_{0}\left(1-e^{-t / \tau}\right)+I_{b g}
$$

Where $I_{(\mathrm{t})}$ is intensity at a given time point; t, time; $I_{0}$, amplitude of the intensity; $\tau$, recovery time; $I_{\mathrm{bg}}$, background intensity.

Strip FRAP: When point FRAP recoveries were too fast to provide accurate mobility data, a strip FRAP protocol was followed. These FRAP measurements for histone H1-GFP were carried out on an Olympus FluoView 1000 confocal microscope as described previously ${ }^{18}$ with a minor modification; 10 images $(512 \times 512$ pixels, $4 \mu \mathrm{s} /$ pixel, $)$ were collected before bleaching, followed by 15 bleaching images in a ROI $(25 \times 12$ pixels, $20 \mu$ s/pixel, $56 \mu \mathrm{W})$ and 80 post-bleach images.

FRAP measurements for EGFP-RAR $\alpha$ and EGFP dimers were also carried out in a similar setting with some modifications. In brief, measurements were performed on a Zeiss LSM 880 (Carl Zeiss, Jena, Germany) confocal microscope using a 40×, 1.2 NA water immersion objective. The $488 \mathrm{~nm}$ laser line was used to excite EGFP with a laser power of $2 \mu \mathrm{W}$ at the objective (10\%), and emission was detected through a 493 to $529 \mathrm{~nm}$ band pass filter. For quantitative analysis, a 256×256-pixel 
area was selected and scanned with an open pinhole (5.56 Airy units) and 10× zoom (pixel size: $0.08 \mu \mathrm{m}$ ), with a pixel dwell time of $1.33 \mu \mathrm{s}$. A 405-nm laser was used to bleach the EGFP molecules at a selected strip-shaped region of interest (FRAP ROI) having an area of $140 \times 10$ pixels, a laser power of $20 \mu \mathrm{W}$ at the objective, and a pixel dwell time of $8.24 \mu$ s. Before bleaching, 10 images were collected at a repetition rate of $204.8 \mathrm{~ms} /$ frame followed by one bleach period at the FRAP ROI, and then collecting 189 post-bleach images for a total time of 42 seconds. To standardize the geometry of the measurement, the scanned field was rotated to make the long axis of the selected nucleus vertically oriented in the image, and the strip shaped FRAP ROI (bleached area) was positioned horizontally at one third of the vertical extension of the nucleus, avoiding nucleoli, (Fig. S10).

Images were processed using the open-source FIJI distribution of ImageJ (version 2.0.0-rc69/1.52i) to acquire the fluorescence intensity recovery curves required for FRAP analysis. The width of the FRAP ROI was cropped to match the width of the nucleus. Another ROI contouring the whole nucleus but excluding the nucleoli was made to calculate the total fluorescence intensity of the nucleus. A third ROI outside the cell was drawn to calculate the intensity of the background. Following the double normalization method $^{53}$ the intensity in the FRAP ROI during the recovery period was normalized to its pre-bleach value $I_{R O I}(0)$, and corrected for acquisition bleaching of the whole nucleus using the following equation:

$$
I_{\text {norm }}(t)=\frac{I_{R O I}(t)-I_{B}}{I_{R O I}(0)-I_{B}} \times \frac{I_{\text {total }}(0)-I_{B}}{I_{\text {total }}(t)-I_{B}}
$$

where $I_{R O I}(t)$ is intensity of the FRAP ROI at a given time during the recovery, $I_{R O I}(0)$ is average intensity of the ROI before bleaching, $I_{\text {total }}(t)$ is the intensity of the whole nucleus at a given time during recovery, $I_{\text {total }}(0)$ is the average intensity of the whole nucleus before bleaching over ten frames, and $I_{B}$ is average intensity of the background. Using the Prism version 8.4.0 software, a two-component exponential curve (eq. 3) was fitted to the normalized recovery curve of the EGFPRAR while a one-component exponential to the EGFP dimer:

$$
I_{\text {norm }}(t)=\left(I_{\min }-I_{\infty}\right) \times\left(r_{\text {fast }} \exp \left(-t / \tau_{\text {fast }}\right)+r_{\text {slow }} \exp \left(-t / \tau_{\text {slow }}\right)\right)+I_{\infty}
$$


The fit yielded the $\tau_{\text {fast }}$ and $\tau_{\text {slow }}$ recovery times of the fast and the slow components, their fractions $r_{\text {fast }}$ and $r_{\text {slow }}$ adding up to 1 , the plateau $I_{\infty}$ at infinite time and the fitted intensity value right after bleaching, $I_{\min }$. The mobile fraction was determined as:

$$
r_{\text {mobile }}=\left(I_{\infty}-I_{\min }\right) /\left(1-I_{\min }\right)
$$

The average recovery time was calculated as a weighted average of the fast and slow components:

$$
\tau_{\text {average }}=r_{\text {fast }} \tau_{\text {fast }}+r_{\text {slow }} \tau_{\text {slow }}
$$

Fluorescence correlation spectroscopy (FCS): FCS measurements were carried out in $300 \mu 1$ volume on an 8-well chamber at room temperature. For the in vitro setting, $1 \mu \mathrm{g}$ of native pEGFPC3 plasmid DNA and 945 ng of Alexa 647 labelled rHMGB1 were mixed in protein binding buffer with or without doxorubicin. The mixture was allowed to equilibrate at RT for $1 \mathrm{hr}$ before measurement. For the in vivo setting, HeLa cells expressing EGFP-RAR or EGFP dimer, treated with 0 or $200 \mu \mathrm{M} \mathrm{H} 2 \mathrm{O} 2$ were examined for a maximal duration of $20 \mathrm{~min}$.

FCS measurements were carried out on a Nikon A1 Eclipse Ti2 confocal laser-scanning microscope (Nikon, Tokyo, Japan), equipped with a Plan Apo 60× water objective [NA=1.27] and a PicoQuant - TCSPC-FCS upgrade kit (PicoQuant, Berlin, Germany). EGFP and Alexa 647 were excited by the $488 \mathrm{~nm}$ and $633 \mathrm{~nm}$ lasers, respectively. The fluorescence emission was filtered through 488-546 $\mathrm{nm}$ and 650-700 $\mathrm{nm}$ band width filters and detected with single photon counting detectors (PicoQuant, Berlin, Germany). Measurements of $10 \times 8$ s runs were taken at a point in the solution/cell. Fluorescence autocorrelation curves were calculated with the SymPhoTime64 software (PicoQuant, Berlin, Germany) at 200 time points from 300 ns to 1 s with quasilogarithmic time scale. Autocorrelation curves were fitted to a model with triplet state and two diffusion components to account for DNA-bound (slow component) and freely diffusing (fast component) proteins.

$$
G(\tau)=\frac{1-T+T e^{-\frac{\tau}{\tau_{t r}}}}{N(1-T)}\left(\rho \frac{1}{1+\frac{\tau}{\tau_{D 1}}} \frac{1}{\sqrt{1+\frac{\tau}{S^{2} \tau_{D 1}}}}+(1-\rho) \frac{1}{\sqrt{1+\frac{\tau}{\tau_{D 2}}}} \frac{1}{\sqrt{1+\frac{\tau}{S^{2} \tau_{D 2}}}}\right)
$$


where $N$ is the average number of fluorescent molecules in the detection volume, $T$ is the fraction of molecules in the triplet state, $\tau_{t r}$ is the triplet correlation time. The rate of diffusion is characterized by the diffusion time, $\tau_{d}$, which is the average time that a molecule spends in the illuminated volume. $\tau_{D 1}$ and $\tau_{D 2}$ are the diffusion times of the fast and slow components, $\rho$ is the fraction of the first component and $1-\rho$ is the fraction of the second component. Diffusion coefficients $(D)$ of the fast and slow components were determined from the following equation:

$$
D=\frac{\omega_{x y}^{2}}{4 \tau_{d}}
$$

Where $\omega_{x y}$ is the lateral $\mathrm{e}^{-2}$ radius of the detection volume. $\omega_{x y}$ was measured by determining the diffusion time of $100 \mathrm{nM}$ Alexa 488 (for calibrating EGFP-RAR $\alpha$ diffusion) or Alexa 647 dye (dissolved in $10 \mathrm{mM}$ Tris-EDTA buffer, $\mathrm{pH} 7.4$ ) with a known diffusion coefficient $\left(D_{\mathrm{A} 647}=309.1\right.$ $\mu \mathrm{m}^{2} / \mathrm{s}{ }^{54,55}, D_{\mathrm{A} 488}=435 \mu \mathrm{m}^{2} / \mathrm{s}{ }^{56}$ at $\mathrm{T}=22.5^{\circ} \mathrm{C}$ ) and substituting them into eq. 3 . All correlation curves were fitted using the free QuickFit 3.0 software $^{57}$. FRAP and FCS data were plotted using GraphPad Prism version 8.0.2.

Expression and purification of rHMGB1: The pET19b expression vector carrying the full length human HMGB1 gene with C23S, C45S, C106S and E204C mutations (kindly provided by Jennifer Kugel at University of Colorado Boulder, USA) was transformed into Rossetta (DE3)pLysS and grown overnight at $37^{\circ} \mathrm{C}$ incubator on LB agar plates containing $100 \mu \mathrm{g} / \mathrm{ml}$ ampicililin and 37.4 $\mu \mathrm{g} / \mathrm{ml}$ chloramphenicol. A single transformed colony from the plate was used to inoculate $5 \mathrm{ml}$ LB with antibiotic. The small culture was incubated overnight at $37{ }^{\circ} \mathrm{C}$ with shaking. The small culture was used to inoculate $100 \mathrm{ml}$ of LB containing D glucose $(100 \mathrm{ml} \mathrm{LB}, 2.4 \mathrm{mM} \mathrm{NaOH}, 0.2$ $\mathrm{g}$ D-glucose) and antibiotic in a $500 \mathrm{ml}$ culture flask. The culture was grown at $37^{\circ} \mathrm{C}$ with shaking until an OD600 of 0.5 was attained upon which expression was induced using 0.5 mM IPTG and the cells were grown for a further 3 hours. The culture was transferred into $50 \mathrm{ml}$ centrifuge tubes and pelleted at 5000 RPM for $15 \mathrm{~min}$. The supernatant was discarded leaving a small volume to resuspend the pellet in. The cells were then transferred into a $1.5 \mathrm{ml}$ Eppendorf tube and pelleted again. The supernatant was discarded, the pellet flash-frozen and stored at $-80^{\circ} \mathrm{C}$. 
To extract the protein, $2 \mathrm{ml}$ of lysis buffer ( $20 \mathrm{mM}$ Tris $\mathrm{pH} 7.9,500 \mathrm{ml} \mathrm{NaCl}, 10 \%$ glycerol, $5 \mathrm{mM}$ imidazole, $5 \mathrm{mM}$ beta mercaptoethanol (BME) and $0.2 \mathrm{mM}$ PMSF) was added to a thawed pellet from $100 \mathrm{ml}$ culture, the pellet was resuspended then the cells sonicated $5 \mathrm{x}$ on ice $(30 \mathrm{~s}$ on, $30 \mathrm{~s}$ off). The lysate was then centrifuged for $15 \mathrm{~min}$ at $4^{\circ} \mathrm{C}$ at $15000 \mathrm{RPM}$. The supernatant containing the protein was transferred into a packed Nickel column and then kept at $4^{\circ} \mathrm{C}$ for $1 \mathrm{hr}$ with rocking motion. The supernatant was allowed to flow through, then the resin washed with $1 \mathrm{ml}$ of lysis buffer followed by $3 \mathrm{ml}$ of lysis buffer containing $50 \mathrm{mM}$ imidazole. The protein was eluted using lysis buffer containing $250 \mathrm{mM}$ imidazole. The column was stripped with lysis buffer supplemented with $1 \mathrm{M}$ imidazole.

Following elution from the nickel column, the buffer was exchanged using a 10K MWCO spin column and $50 \mathrm{ml}$ degassed dialysis buffer (20 mM Tris pH 7.9, $50 \mathrm{mM} \mathrm{KCL}, 10 \%$ glycerol, 100 $\mathrm{mM}$ PMSF, $100 \mathrm{mM} \mathrm{MgCl} 2$ and $1 \mathrm{mM} \mathrm{DTT}$ ). After buffer exchange the protein sample in about $250 \mu \mathrm{l}$ was centrifuged at $18,000 \mathrm{RPM}$ for $30 \mathrm{~min}$ at $4^{\circ} \mathrm{C}$ and the supernatant transferred to a dsDNA cellulose column and incubated for $1 \mathrm{hr}$ at $4^{\circ} \mathrm{C}$ with rocking motion. The supernatant was allowed to flow through, the resin washed $3 \mathrm{x}$ with $3 \mathrm{ml}$ wash buffer $(20 \mathrm{mM}$ Tris $\mathrm{pH}$ 7.9, $50 \mathrm{mM}$ $\mathrm{NaCl}, 10 \%$ glycerol, $5 \mathrm{mM} \mathrm{MgCl}_{2}$ and $1 \mathrm{mM}$ DTT) and the protein eluted using wash buffer with $500 \mathrm{mM} \mathrm{NaCl}$. The column was stripped with wash buffer containing $1 \mathrm{M} \mathrm{KCl}$. The protein was then desalted using 10K MWCO spin column and degassed dialysis buffer as above without DTT. Purification was confirmed using a 12\% SDS PAGE gel electrophoresed for $1 \mathrm{hr}$ at $150 \mathrm{~V}$. Samples were centrifuged at $18,000 \mathrm{RPM}$ for $30 \mathrm{~min}$ at $4^{\circ} \mathrm{C}$, aliquoted, flash frozen and stored at $-80^{\circ} \mathrm{C}$. Quantification was carried out using Lowry assay and known amounts of BSA controls. Measurements were also made on the Nanodrop.

Immunofluorescence labelling of rHMGB1: Labelling of rHMGB1 with Alexa 647 C2 maleimide (Thermo scientific) was done following the manufacturer's instructions. To reduce the disulphide bonds in the protein, $750 \mu \mathrm{g}$ of rHMGB1 in degassed buffer A (100mM Tris pH 7.1, $50 \mathrm{mM} \mathrm{KCl}, 10 \%$ glycerol, $0.2 \mathrm{mM} \mathrm{PMSF}$ and $5 \mathrm{mM} \mathrm{MgCl}_{2}$ ) was mixed with DTT to a final concentration of $10 \mathrm{mM}$ and incubated at $4^{\circ} \mathrm{C}$ for $2 \mathrm{hrs}$. DTT was removed using a spin column and $20 \mathrm{ml}$ buffer A. $1.5 \mu \mathrm{l}$ of $8 \mathrm{mM}$ Alexa $647 \mathrm{C} 2$ maleimide was added to the sample and incubated in the dark at $4{ }^{\circ} \mathrm{C}$ overnight. Unbound dye was removed using 10K MWCO microfuge spin column and sample washed with column wash buffer $(20 \mathrm{mM}$ Tris $\mathrm{pH} 7.9,50 \mathrm{mM} \mathrm{KCl}$ and 
$5 \mathrm{mM} \mathrm{MgCl} 2$ ). Samples were quantified by measuring absorbance at $280 \mathrm{~nm}$ and compared to a standard curve prepared from known amounts of BSA. Glycerol was added to a final concentration of $10 \%$ and samples stored at either $-20^{\circ} \mathrm{C}$ for short term or $-80^{\circ} \mathrm{C}$ for long-term storage.

Electrophoretic mobility shift assay (EMSA): To determine the binding affinity of the labelled rHMGB1 to various topological forms of plasmid DNA, gel electrophoresis was carried out. Native pEGFP C3 plasmid DNA was either nicked or linearized using Nb.Mva1269I and ECoRI (Thermo scientific), respectively, using the manufacturer's instructions. The DNA samples were then cleaned using gel cleaning kit (QIAGEN) following the manufacturer's instructions. DNA was quantified by measuring the absorbance at $260 \mathrm{~nm}$ on the Nanodrop. An equal amount $(0.5$ $\mu \mathrm{g}$ ) of linear, nicked and native plasmid DNA was mixed in $20 \mu \mathrm{l}$ of protein binding buffer $(50 \mathrm{mM}$ $\mathrm{NaCl}, 20 \mathrm{mM}$ Tris $\mathrm{HCl} \mathrm{pH} 7.5$ and $0.2 \mathrm{mM}$ EDTA). To this DNA mixture, varying amounts of rHMGB1 was added per sample as indicated on the gel (Fig. S2) and incubated on ice for $40 \mathrm{~min}$ on ice. The samples were then loaded to a $1 \%$ agarose gel in $0.5 \mathrm{x}$ TBE and run for at $36 \mathrm{~V}$ for 15 hours at $4^{\circ} \mathrm{C}$. The gel was stained with $0.5 \mu \mathrm{g} / \mathrm{ml} \mathrm{EBr}$ and then imaged. The image was processed using Fiji ImageJ.

Statistical analysis: For creating plots and for statistical comparisons GraphPad Prism 8.01 was used. Box-and-whiskers plots represent $10^{\text {th }}, 25^{\text {th }}, 50^{\text {th }}, 75^{\text {th }}$, and $90^{\text {th }}$ percentiles; + , mean value. To compare averages of multiple data sets, ANOVA with Tukey's multiple comparison test was used. 
Acknowledgements: We wish to thank Adél Vezendiné Nagy and Edina Nagy for excellent technical assistance. Grant support: GINOP-2.3.2-15-2016-00026, NN129371, ANN135107 from the National Research, Development and Innovation Office, Hungary (to GV), GINOP-2.3.2-15-2016-00044, OTKA K128770 and COST CA 15214 (to GS) and Stipendium Hungaricum scholarship by the Tempus Public Foundation (to RB, LF, PS, AKS, MUN). GK is supported by the Ligue contre le Cancer (équipe labellisée); Agence National de la Recherche (ANR) - Projets blancs; AMMICa US23/CNRS UMS3655; Association pour la recherche sur le cancer (ARC); Association "Ruban Rose"; Cancéropôle Ile-de-France; Fondation pour la Recherche Médicale (FRM); a donation by Elior; Equipex Onco-Pheno-Screen; European Joint Programme on Rare Diseases (EJPRD); Gustave Roussy Odyssea, the European Union Horizon 2020 Projects Oncobiome and Crimson; Fondation Carrefour; Institut National du Cancer (INCa); Inserm (HTE); Institut Universitaire de France; LabEx Immuno-Oncology (ANR-18-IDEX-0001); the Leducq Foundation; a Cancer Research ASPIRE Award from the Mark Foundation; the RHU Torino Lumière; Seerave Foundation; SIRIC Stratified Oncology Cell DNA Repair and Tumor Immune Elimination (SOCRATE); and SIRIC Cancer Research and Personalized Medicine (CARPEM). This study contributes to the IdEx Université de Paris ANR-18-IDEX-0001.

\section{Author contributions}

R.B. did experiments regarding HMGB1 and H1, data analysis \& writing, L.F. did experiments regarding RAR and EGFP dimers and doxorubicin, data analysis \& writing, G.M. developed software for point FRAP \& matlab script for data analysis, P.N. methodology, P.S. \& A.K.S. did experiments regarding RAR and EGFP dimers \& M.U.N. experimentation regarding rHMGB1 purification, A.K. carried out X-ray irradiation, J.K. \& G.K. (plasmid \& cell line respectively), G.V. \& G.S. experimental design \& manuscript writing and review.

\section{Competing interests}

The authors have no competing interests. 


\section{References}

1 Bosire, R. et al. Intercalation of small molecules into DNA in chromatin is primarily controlled by superhelical constraint. PLoS One 14, e0224936, doi:10.1371/journal.pone.0224936 (2019).

2 Rohs, R. et al. Origins of specificity in protein-DNA recognition. Annu Rev Biochem 79, 233-269, doi:10.1146/annurev-biochem-060408-091030 (2010).

3 Lavery, R., Moakher, M., Maddocks, J. H., Petkeviciute, D. \& Zakrzewska, K. Conformational analysis of nucleic acids revisited: Curvest. Nucleic Acids Res 37, 5917-5929, doi:10.1093/nar/gkp608 (2009).

4 Lu, X. J. \& Olson, W. K. 3DNA: a software package for the analysis, rebuilding and visualization of three-dimensional nucleic acid structures. Nucleic Acids Res 31, 5108-5121, doi:10.1093/nar/gkg680 (2003).

5 Liebl, K., Drsata, T., Lankas, F., Lipfert, J. \& Zacharias, M. Explaining the striking difference in twist-stretch coupling between DNA and RNA: A comparative molecular dynamics analysis. Nucleic Acids Res 43, 10143-10156, doi:10.1093/nar/gkv1028 (2015).

6 Catez, F. et al. Network of dynamic interactions between histone H1 and high-mobility-group proteins in chromatin. Mol Cell Biol 24, 4321-4328, doi:10.1128/MCB.24.10.4321-4328.2004 (2004).

7 Hergeth, S. P. \& Schneider, R. The H1 linker histones: multifunctional proteins beyond the nucleosomal core particle. EMBO Rep 16, 1439-1453, doi:10.15252/embr.201540749 (2015).

8 Agresti, A. \& Bianchi, M. E. HMGB proteins and gene expression. Curr Opin Genet Dev 13, 170178, doi:10.1016/s0959-437x(03)00023-6 (2003).

9 Ivanchenko, M., Zlatanova, J. \& van Holde, K. Histone H1 preferentially binds to superhelical DNA molecules of higher compaction. Biophys $J$ 72, 1388-1395, doi:10.1016/S00063495(97)78785-X (1997).

10 Lange, S. S. \& Vasquez, K. M. HMGB1: the jack-of-all-trades protein is a master DNA repair mechanic. Mol Carcinog 48, 571-580, doi:10.1002/mc.20544 (2009).

11 Sanchez-Giraldo, R. et al. Two high-mobility group box domains act together to underwind and kink DNA. Acta Crystallogr D Biol Crystallogr 71, 1423-1432, doi:10.1107/S1399004715007452 (2015).

12 Singh, R. K., Sasikala, W. D. \& Mukherjee, A. Molecular Origin of DNA Kinking by Transcription Factors. J Phys Chem B 119, 11590-11596, doi:10.1021/acs.jpcb.5b06229 (2015).

13 Fulton, D. L. et al. TFCat: the curated catalog of mouse and human transcription factors. Genome Biol 10, R29, doi:10.1186/gb-2009-10-3-r29 (2009).

14 Dickerson, R. E. DNA bending: the prevalence of kinkiness and the virtues of normality. Nucleic Acids Res 26, 1906-1926, doi:10.1093/nar/26.8.1906 (1998).

15 Siggers, T. \& Gordan, R. Protein-DNA binding: complexities and multi-protein codes. Nucleic Acids Res 42, 2099-2111, doi:10.1093/nar/gkt1112 (2014).

16 Rastinejad, F., Wagner, T., Zhao, Q. \& Khorasanizadeh, S. Structure of the RXR-RAR DNAbinding complex on the retinoic acid response element DR1. EMBO J 19, 1045-1054, doi:10.1093/emboj/19.5.1045 (2000).

17 Nagy, L. \& Schwabe, J. W. Mechanism of the nuclear receptor molecular switch. Trends Biochem Sci 29, 317-324, doi:10.1016/j.tibs.2004.04.006 (2004).

18 Brazda, P. et al. Ligand binding shifts highly mobile retinoid X receptor to the chromatin-bound state in a coactivator-dependent manner, as revealed by single-cell imaging. Mol Cell Biol 34, 12341245, doi:10.1128/MCB.01097-13 (2014).

19 Brazda, P. et al. Live-cell fluorescence correlation spectroscopy dissects the role of coregulator exchange and chromatin binding in retinoic acid receptor mobility. J Cell Sci 124, 3631-3642, doi:10.1242/jcs.086082 (2011). 
20 Fadel, L. et al. Agonist binding directs dynamic competition among nuclear receptors for heterodimerization with retinoid X receptor. J Biol Chem 295, 10045-10061, doi:10.1074/jbc.RA119.011614 (2020).

21 Reho, B. et al. Simultaneous Mapping of Molecular Proximity and Comobility Reveals AgonistEnhanced Dimerization and DNA Binding of Nuclear Receptors. Anal Chem 92, 2207-2215, doi:10.1021/acs.analchem.9b04902 (2020).

22 Magdy, T. et al. RARG variant predictive of doxorubicin-induced cardiotoxicity identifies a cardioprotective therapy. Cell Stem Cell 28, 2076-2089 e2077, doi:10.1016/j.stem.2021.08.006 (2021).

23 Giuli, M. V. et al. Current Trends in ATRA Delivery for Cancer Therapy. Pharmaceutics 12, doi:10.3390/pharmaceutics12080707 (2020).

24 Yang, L. et al. All-trans retinoic acid protects against doxorubicin-induced cardiotoxicity by activating the ERK2 signalling pathway. Br J Pharmacol 173, 357-371, doi:10.1111/bph.13377 (2016).

25 Aminkeng, F. et al. A coding variant in RARG confers susceptibility to anthracycline-induced cardiotoxicity in childhood cancer. Nat Genet 47, 1079-1084, doi:10.1038/ng.3374 (2015).

26 Imre, L. et al. Nucleosome stability measured in situ by automated quantitative imaging. Sci Rep 7, 12734, doi:10.1038/s41598-017-12608-9 (2017).

27 Szekvolgyi, L. et al. Ribonucleoprotein-masked nicks at 50-kbp intervals in the eukaryotic genomic DNA. Proc Natl Acad Sci U S A 104, 14964-14969, doi:10.1073/pnas.0702269104 (2007).

28 Wojcik, K., Zarebski, M., Cossarizza, A. \& Dobrucki, J. W. Daunomycin, an antitumor DNA intercalator, influences histone-DNA interactions. Cancer Biol Ther 14, 823-832, doi:10.4161/cbt.25328 (2013).

29 Happel, N. \& Doenecke, D. Histone H1 and its isoforms: contribution to chromatin structure and function. Gene 431, 1-12, doi:10.1016/j.gene.2008.11.003 (2009).

30 Leid, M. et al. Purification, cloning, and RXR identity of the HeLa cell factor with which RAR or TR heterodimerizes to bind target sequences efficiently. Cell 68, 377-395, doi:10.1016/00928674(92)90478-u (1992).

31 Frederick, C. A. et al. Structural comparison of anticancer drug-DNA complexes: adriamycin and daunomycin. Biochemistry 29, 2538-2549 (1990).

32 Pommier, Y., Sun, Y., Huang, S. N. \& Nitiss, J. L. Roles of eukaryotic topoisomerases in transcription, replication and genomic stability. Nat Rev Mol Cell Biol 17, 703-721, doi:10.1038/nrm.2016.111 (2016).

33 Wang, J. C. Cellular roles of DNA topoisomerases: a molecular perspective. Nat Rev Mol Cell Biol 3, 430-440, doi:10.1038/nrm831 (2002).

34 Pommier, Y., Leo, E., Zhang, H. \& Marchand, C. DNA topoisomerases and their poisoning by anticancer and antibacterial drugs. Chem Biol 17, 421-433, doi:10.1016/j.chembiol.2010.04.012 (2010).

35 Nanasi, P., Jr. et al. Doxorubicin induces large-scale and differential H2A and H2B redistribution in live cells. PLoS One 15, e0231223, doi:10.1371/journal.pone.0231223 (2020).

36 Pang, B. et al. Drug-induced histone eviction from open chromatin contributes to the chemotherapeutic effects of doxorubicin. Nat Commun 4, 1908, doi:10.1038/ncomms2921 (2013).

37 Stros, M. HMGB proteins: interactions with DNA and chromatin. Biochim Biophys Acta 1799, 101-113, doi:10.1016/j.bbagrm.2009.09.008 (2010).

38 Malarkey, C. S. \& Churchill, M. E. The high mobility group box: the ultimate utility player of a cell. Trends Biochem Sci 37, 553-562, doi:10.1016/j.tibs.2012.09.003 (2012).

39 McGrath, R. A. \& Williams, R. W. Reconstruction in vivo of irradiated Escherichia coli deoxyribonucleic acid; the rejoining of broken pieces. Nature 212, 534-535, doi:10.1038/212534a0 (1966). 
Dahm-Daphi, J., Sass, C. \& Alberti, W. Comparison of biological effects of DNA damage induced by ionizing radiation and hydrogen peroxide in CHO cells. Int J Radiat Biol 76, 67-75, doi:10.1080/095530000139023 (2000).

41 Caldecott, K. W. Single-strand break repair and genetic disease. Nat Rev Genet 9, 619-631, doi:10.1038/nrg2380 (2008).

42 Liu, L. F. \& Wang, J. C. Supercoiling of the DNA template during transcription. Proc Natl Acad Sci U S A 84, 7024-7027, doi:10.1073/pnas.84.20.7024 (1987).

43 Wang, L. et al. Ionizing Radiation Induces HMGB1 Cytoplasmic Translocation and Extracellular Release. Guo Ji Fang She Yi Xue He Yi Xue Za Zhi 40, 91-99 (2016).

44 Tang, D. et al. Hydrogen peroxide stimulates macrophages and monocytes to actively release HMGB1. J Leukoc Biol 81, 741-747, doi:10.1189/jlb.0806540 (2007).

45 Nagpal, S. et al. Retinoid-dependent recruitment of a histone H1 displacement activity by retinoic acid receptor. J Biol Chem 274, 22563-22568, doi:10.1074/jbc.274.32.22563 (1999).

46 Vamosi, G. et al. Conformation of the c-Fos/c-Jun complex in vivo: a combined FRET, FCCS, and MD-modeling study. Biophys J 94, 2859-2868, doi:10.1529/biophysj.107.120766 (2008).

47 Pernus, A. \& Langowski, J. Imaging Fos-Jun transcription factor mobility and interaction in live cells by single plane illumination-fluorescence cross correlation spectroscopy. PLoS One 10, e0123070, doi:10.1371/journal.pone.0123070 (2015).

48 Baudendistel, N., Muller, G., Waldeck, W., Angel, P. \& Langowski, J. Two-hybrid fluorescence cross-correlation spectroscopy detects protein-protein interactions in vivo. Chemphyschem 6, 984990, doi:10.1002/cphc.200400639 (2005).

49 Greene, R. F., Collins, J. M., Jenkins, J. F., Speyer, J. L. \& Myers, C. E. Plasma pharmacokinetics of adriamycin and adriamycinol: implications for the design of in vitro experiments and treatment protocols. Cancer Res 43, 3417-3421 (1983).

50 Silva, E. F., Bazoni, R. F., Ramos, E. B. \& Rocha, M. S. DNA-doxorubicin interaction: New insights and peculiarities. Biopolymers 107, doi:10.1002/bip.22998 (2017).

51 Octavia, Y. et al. Doxorubicin-induced cardiomyopathy: from molecular mechanisms to therapeutic strategies. J Mol Cell Cardiol 52, 1213-1225, doi:10.1016/j.yjmcc.2012.03.006 (2012).

52 Christidi, E. et al. Variation in RARG increases susceptibility to doxorubicin-induced cardiotoxicity in patient specific induced pluripotent stem cell-derived cardiomyocytes. Sci Rep 10, 10363, doi:10.1038/s41598-020-65979-x (2020).

53 Phair, R. D., Gorski, S. A. \& Misteli, T. Measurement of dynamic protein binding to chromatin in vivo, using photobleaching microscopy. Methods Enzymol 375, 393-414, doi:10.1016/s00766879(03)75025-3 (2004).

54 Loman, A. Molecular Sizing using Fluorescence Correlation Spectroscopy, Georg-AugustUniversität Göttingen (2010).

55 Kapusta, P. Absolute Diffusion Coefficients: Compilation of Reference Data for FCS. Picoquant GmbH (2010).

56 Petrasek, Z. \& Schwille, P. Precise measurement of diffusion coefficients using scanning fluorescence correlation spectroscopy. Biophys J 94, 1437-1448, doi:10.1529/biophysj.107.108811 (2008). 


\section{Supplementary Files}

This is a list of supplementary files associated with this preprint. Click to download.

- BosireetalSupplementalmaterial.pdf 